\title{
CARACTERIZAÇÃO FÍSICA DOS RESÍDUOS SÓLIDOS DOMÉSTICOS E DIMENSIONAMENTO DE ÁREA PARA ATERRO SANITÁRIO NO MUNICÍPIO DE SOBRADINHO-BA
}

\author{
Iara Jeanice Souza Ferreira ${ }^{1 *}$, Emanuela Gonçalves ${ }^{1}$, Heitor de Santana Rodrigues ${ }^{2}$, Miriam Cleide Cavalcante de Amorim ${ }^{1}$ \\ ${ }^{1}$ Departamento de Engenharia Agrícola e Ambiental, Universidade Federal do Vale do São Francisco, 48902-300, Juazeiro, Brasil. \\ ${ }^{2}$ Departamento de Engenharia Civil, Universidade Federal do Vale do São Francisco, 48902-300, Juazeiro, Brasil.
}

*E-mail: iarajeanice@hotmail.com

\section{RESUMO}

Os diversos transtornos promovidos pelo acúmulo indevido dos resíduos sólidos urbanos, em decorrência do acelerado aumento populacional, associados à realidade gerencial do país, tornam os desequilíbrios perceptíveis. Nesse âmbito, o presente estudo objetivou realizar uma caracterização física dos resíduos domiciliares e estimar área voltada à implantação de aterro sanitário de pequeno porte para o município de Sobradinho-BA. O diagnóstico gravimétrico se consolidou em três sessões quinzenais por coletas porta a porta, em 70 domicílios da sede municipal, amostrados em $90 \%$ de confiança. A área do aterro foi estimada a partir da produção futura e da geração per capita dos resíduos amostrados. A sede gera em torno de $0,72 \mathrm{~kg} / \mathrm{hab}$./dia de resíduos. A quantidade total obtida constituiu-se em $62 \%$ de resíduos orgânicos, $20 \%$ de rejeitos, $8 \%$ de material reciclável caracterizado como plástico e $10 \%$ de outros tipos de materiais. $\mathrm{O}$ maior acréscimo em massa de resíduos se deu durante os festejos juninos. O cálculo de estimativa da área para o aterro demonstrou ser necessário utilizar $111 \mathrm{~m}^{2}$. O trabalho agrega informações ausentes para o município, visando contribuir com a elaboração do Plano de Saneamento Básico da Região Integrada de Desenvolvimento Econômico.

Palavras-chave: Resíduos Sólidos. Gravimetria. Aterro de pequeno porte.

\section{Introdução}

A conjuntura ambiental atual tem demonstrado que as preocupações em torno da problemática envolvendo resíduos sólidos tornam-se cada vez mais frequentes. A Lei n ${ }^{\circ} 11.445$ de 5 de janeiro de 2007, que estabelece as diretrizes nacionais para o saneamento básico e o define como um conjunto de serviços, infraestruturas e instalações operacionais de abastecimento de água potável, esgotamento sanitário, limpeza pública e manejo dos resíduos sólidos, assim como drenagem e manejo das águas pluviais, considera, como eixos que compõem o setor de resíduos, as infraestruturas e as instalações operacionais de coleta, o transporte, o transbordo, o tratamento e o destino final do resíduo doméstico e do resíduo originário da varrição e limpeza de logradouros e vias públicas [1].

Em seus artigos 52 e 53, respectivamente, a supracitada lei designa também dois importantes instrumentos legais, que são: a necessidade de elaboração dos Planos de Saneamento Básico; e a disponibilidade de um Sistema de Informações baseado no princípio da transparência e do livre acesso, que, atualmente, é representado pelo Sistema Nacional de Informações sobre Saneamento (SNIS).
Por meio da Lei Federal do Saneamento Básico, $\mathrm{n}^{\circ}$ 11.445/07[1], as chamadas Regiões Integradas de Desenvolvimento Econômico (RIDEs) também foram criadas pela necessidade de aderir às estratégias descentralizadas, unindo ações administrativas da União, dos Estados e Municípios, no intuito de expandir as políticas públicas para o desenvolvimento econômico e social de complexos geoeconômicos de mais de uma unidade federativa [2].

O Brasil detém três RIDEs, as quais se situam em regiões, unidas geograficamente, do Distrito Federal e proximidades (Lei $\mathrm{n}^{\circ}$ 94/98), da Grande Teresina (Lei $\mathrm{n}^{\circ}$ 112/91) e de Petrolina/Juazeiro (Lei ${ }^{\circ}$ 113/010). A elaboração obrigatória dos Planos de Saneamento para cada uma dessas Regiões Integradas, conforme estabelece a Lei do Saneamento no inciso II do artigo 52, deverá advir da descentralização de recursos para diferentes instituições universitárias que as integram e que coordenarão todo o processo de pesquisa [3].

Sob a luz da Lei do Saneamento, com metas claras e bem embasadas, há também, no cenário nacional sobre legislação, a Política Nacional dos Resíduos Sólidos (PNRS), instituída pela Lei $\mathrm{n}^{\circ} 12.305$ de 2 de agosto de 2010, que veio para se configurar 
como importante ferramenta de desenvolvimento de ações que integram a área [4].

Diversos estudos demonstram que, apesar da PNRS definir o gerenciamento como o conjunto de ações exercidas, direta ou indiretamente, ainda não há utilização amplamente consistente de suas premissas. Para os países em desenvolvimento, alguns fatores voltados ao processo de urbanização, ao avanço econômico, às questões culturais, às políticas, ao reduzido conhecimento de tecnologias, à dificuldade em dispor equipamentos para a coleta, à governança e às influências externas comprometeram o setor dos resíduos sólidos municipais [5-6].

A Associação Brasileira das Empresas de Limpeza Pública e Resíduos Especiais (ABRELPE) [7] estima que 3.326 municípios dos mais de 5.000 (ver quantidade correta de municípios brasileiros) dispõem seus resíduos de forma errônea. Um elevado número destes faz parte dos chamados municípios de pequeno porte, que, como classifica o Instituto Brasileiro de Geografia e Estatística (IBGE), possuem população de até 50.000 habitantes. Esses municípios possuem inúmeras contrariedades para implementar e dar seguimento à operação de aterros sanitários (os quais são ambientalmente adequados à destinação), além de terem o costume de gerar grande quantidade de resíduos.

$\mathrm{Na}$ Bahia, dos 59,5\% dos municípios de pequeno porte, com até 20.000 habitantes, e dos 30,2\% que possuem população entre 20.000 e 50.000 habitantes, quase que a totalidade destina seus resíduos de forma inadequada, tendo-se em vista que, em 2013, estimou-se a existência de 359 lixões, como a forma mais usada de disposição final [8].

A seleção de local adequado para a implementação de um aterro sanitário, o qual pode minimizar tal problemática, somase, também, nesse sentido, como um dos principais intervenientes que desafiam tal cenário, pois demanda inúmeros e complexos estudos pedogeológicos, clara aprovação de setores comunitários, além de articulação entre funcionamento e atividades de coleta seletiva para diferentes reaproveitamentos que ampliam sua vida útil [9-10].

Existem aterros denominados de grande porte e outros de pequeno porte, os quais se diferem pelas técnicas metodológicas de instalação adotadas. Quando o método utilizado é o por área, significa que o local apresenta condições topográficas propícias para acondicionar os resíduos, não necessitando de ajustes, e que eles são distribuídos, compactados e recobertos ao longo de todo o terreno disponibilizado. Por outro lado, se o aterro possui conformação em rampas, ocorre que o terreno utilizado é seco e plano, ou seja, necessita ser terraplanado, e que os resíduos são acomodados como células compactadas [11].

Sendo, dentre os anteriormente relatados, um dos métodos mais comumente utilizados, pela maior facilidade de operacionalização, o por trincheira é aquele que:

\footnotetext{
Geralmente é utilizado em áreas planas, onde são escavadas trincheiras ou valas no solo, com dimensões variadas e adequadas ao volume de lixo gerado, de forma a permitir a operação dos equipamentos utilizados na aterragem. As dimensões da trincheira definem os métodos construtivos, a forma de operação e os equipamentos a serem utilizados. Os resíduos podem ser compactados de forma manual ou mecânica, dependendo das dimensões da trincheira. Aterros em trincheira mostram-se adequados a pequenas comunidades, pois podem ser operados de forma manual [11].
}

Kroetz [12] diz que "para se dimensionar trincheiras de aterros sanitários deve-se conhecer as características da área disponível, para saber informações prévias ao cálculo, como a altura em relação ao lençol freático, fator que pode limitar a altura máxima da trincheira."

Um dos processos atrelados e determinantes à implantação de aterros, que deve advir da elaboração de um plano de gestão e gerenciamento de resíduos sólidos urbanos, é o processo de caracterização. Essa etapa permite identificar as propriedades dos resíduos e os enquadrar de forma correta, entre suas características físicas, químicas e biológicas [13]. Campos [14] mostra que questões relacionadas a crises ou a sucessos nos diversos setores da economia afetam o consumo de bens, de alimentos e, por consequência, a geração per capita de resíduos sólidos, que pode, vertiginosamente, aumentar, por exemplo, diante do surgimento de empregos e da elevação salarial. As características exibidas pelos resíduos se diferenciam à medida que diferentes conformações sociais, econômicas, culturais, geográficas e climáticas se manifestam [15]. Colvero et. al [16] identificaram que, no estado de Goiás, quanto menores os municípios, maiores eram suas gerações per capita de resíduos.

Estudos como o de Souza e Tinôco [17], assim como o de Oliveira et al. [18], abordam, respectivamente, a influência frequente e impactante de resíduos de origem festiva no equilíbrio de ambientes aquáticos e a observável variação média do quantitativo que adentra em aterro sanitário durante épocas de comemorações juninas inerentes à região nordeste do país.

Em Gana, na África ocidental, onde a gestão dos resíduos sólidos ainda é inexistente, a caracterização e quantificação de 
resíduos obtidos junto a domicílios de diferentes áreas, aponta haver taxa de produção de $0,47 \mathrm{~kg} /$ pessoa/dia, que translada para uma geração diária de aproximadamente 12,710 toneladas por dia, considerando a população total de 27.043.093 habitantes. Na maioria das metrópoles avaliadas, a taxa de geração mostrouse alta, ficando em torno de $0,72 \mathrm{~kg} /$ pessoa/dia. Já em municípios com menor desenvolvimento, ficou em torno de 0,40 $\mathrm{kg} /$ pessoa/dia. Também foram encontradas diferenças entre regiões geográficas. Enquanto na extensão costeira destacou-se o grande desperdício de componentes orgânicos, nos locais situados mais ao norte da savana ocorreu aumento na quantidade de resíduos plásticos [19].

$\mathrm{Na}$ China, um levantamento das tendências temporais e da caracterização da variação espacial na quantidade de resíduos sólidos em distintas regiões diagnosticou uma geração per capita máxima de $0,6532 \mathrm{~kg} /$ pessoa/dia, em 2014, e 61,2\% de proporção de resíduos alimentares, $9,8 \%$ de plásticos e $9,6 \%$ de papel [20].

Carvalho, Jesus e Portela [21] explanaram acerca da existência de elevado percentual de matéria orgânica putrescível $(63,8 \%)$ para o centro municipal de Barreiras, na Bahia, argumentando haver grande relação disso com a existência de imóveis domiciliares e departamentos de produção alimentícia, que praticam desperdícios.

Dentro desse contexto, tendo em vista a sede do município de Sobradinho-BA, importante membro da Região Integrada de Desenvolvimento Econômico do Vale do São Francisco (RIDE), o trabalho teve como objetivo realizar um diagnóstico do cenário atual de gestão dos Resíduos Sólidos, utilizando a caracterização dos Resíduos Sólidos Domésticos (RSDs) produzidos na sede municipal, a fim de determinar a área necessária para um aterro sanitário, como contribuição à elaboração do Plano de Gestão e Gerenciamento de Resíduos Sólidos da Região Integrada.

\section{Metodologia}

\section{1 Área de estudo}

Todo o processo de pesquisa ocorreu na sede do município de Sobradinho-Ba, que está localizado a 09²7'19" de latitude sul e 4049'24" de longitude oeste, com altitude média de 380 metros.

Com população de 23.713 habitantes [22] e área de $1.154,905 \mathrm{~km}^{2}$, Sobradinho possui zona urbana composta pelas vilas São Joaquim, São Francisco e Santana, as quais apresentam distintas densidades residenciais [23]. Além disso, integra a RIDE Petrolina/Juazeiro (figura 1).

O município agrega o maior Produto Interno Bruto (PIB) per capita da RIDE, pelo fato de abrigar a Usina Hidrelétrica de Sobradinho, considerada uma das maiores do Brasil, bem como o segundo maior lago artificial do mundo [24].

Assim como muitos dos municípios de pequeno porte, Sobradinho ainda não elaborou seu Plano de Saneamento Básico e tampouco o seu Plano de Gestão e Gerenciamento de Resíduos Sólidos Urbanos, destinando tais resíduos a um vazadouro a céu aberto, denominado Lixão Serra Verde [25].

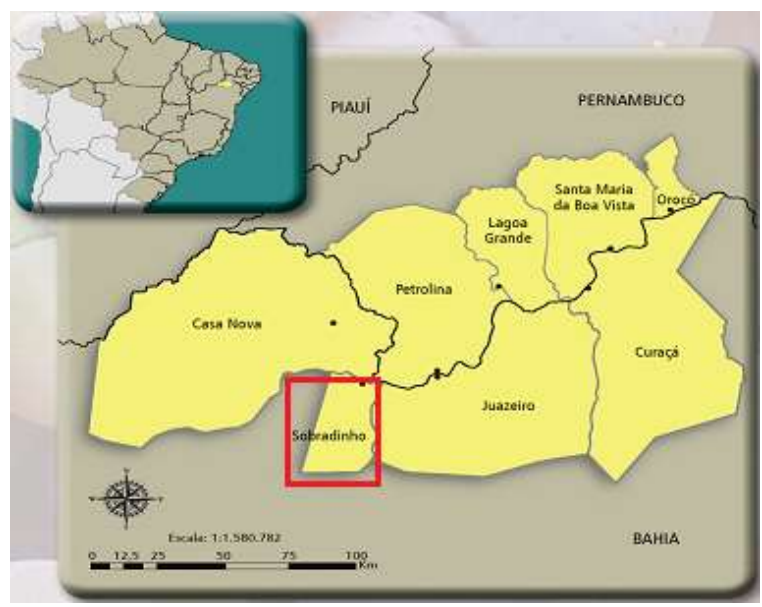

Figura 1- Sobradinho no Polo da RIDE Petrolina/Juazeiro [26].

\subsection{Definição da amostragem para caracterização dos resíduos}

O estudo gravimétrico envolveu residências situadas na sede municipal, nas quais as amostras dos resíduos sólidos domiciliares foram adquiridas. Para delimitar a população universal a ser amostrada, foi feito cálculo probabilístico conforme equação (1) proposta por Palma [27], com margem de erro máximo de $10 \%$ e intervalo de confiança de $90 \%$, utilizando o número total de ligações ativas de água, obtido do banco de dados do Sistema Nacional de Informações sobre Saneamento [25].

$$
N=\frac{\sigma^{2} \cdot p \cdot q \cdot n}{\mathrm{e}^{2}(n-1)+\sigma^{2} \cdot p \cdot q}(1)
$$

Onde, $\mathrm{N}=$ tamanho da amostra, $\sigma^{2}=$ nível de confiança escolhido, expresso em número de desvio padrão $=0,1 ; \mathrm{p}=$ percentagem com a qual o fenômeno se verifica $=0,5 ; \mathrm{q}=$ percentagem complementar $(100-\mathrm{p})=0,5$; e $=$ erro máximo 
permitido $=1,645 ; \mathrm{n}=$ tamanho da população $=6.921$ ligações ativas de água.

O cálculo gerou amostra de 70 domicílios, valor esse, que, apesar de incluir perdas, representa com fidedignidade a sede municipal, pois, como enfatiza Dahlen e Lagerkvist [28] apud Bassani [29], para amostragem que envolve $100 \mathrm{~kg}$ ou mais de resíduos, um número mínimo de 10 amostras costuma ser adotado como regra geral.

O valor total amostrado foi distribuído de maneira proporcional à densidade residencial de cada vila [23], de forma aleatória simples, ficando: a vila São Joaquim com 40 amostras; a vila São Francisco com 20 amostras; e a vila Santana com 10 amostras.

\subsection{Coleta e manuseio das amostras}

Ainda que tenham ocorrido algumas recusas da população em contribuir com o estudo, a amostragem foi alcançada e as sacolas foram entregues em domicílios arbitrariamente selecionados, para se assegurar que todos os residentes da sede tivessem oportunidade de participar.

A entrega de sacolas para acondicionamento dos resíduos e a coleta deles foram consolidadas entre os meses de junho e julho de 2017, em três sessões quinzenais e sucessivas, entre terças e quintas-feiras.

Decorridas quarenta e oito horas pós-entrega, as sacolas foram coletadas e conduzidas para um local apropriado, onde foi realizada a caracterização quantitativa e qualitativa.

Nesse diagnóstico, a segunda sessão quinzenal englobou uma época festiva, a fim de verificar mudanças nos hábitos dos residentes do município dentro do período.

\subsection{Análise gravimétrica}

Muito embora a técnica do quarteamento (NBR 10007/04) [30] seja a mais comumente utilizada, o método de análise gravimétrica adotado foi o por domicílio, como proposto por Franco [31], devido à preocupação com a exata origem dos resíduos e a busca por maior precisão estatística, visto que as coletas foram realizadas porta a porta.

Pelo método, as sacolas eram rompidas sobre uma lona preta, na qual era realizada a separação e pesagem dos diferentes tipos de resíduos sólidos urbanos (Figura 2).

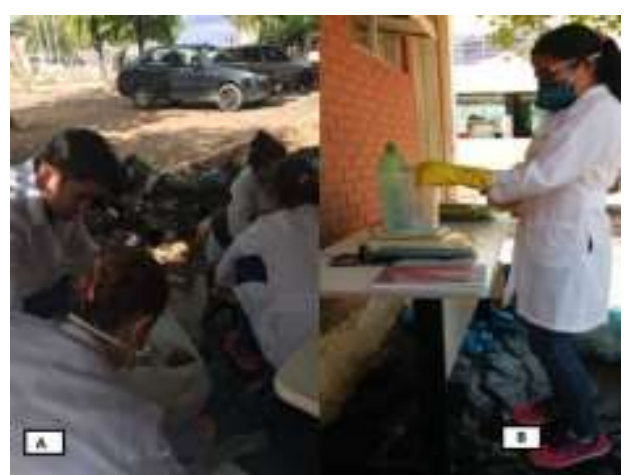

Figura 2 - (A) Rompimento das sacolas e separação dos resíduos; (B) Pesagem dos componentes.

\subsubsection{Geração per capita}

A geração per capita foi determinada através da equação (2), adaptada do SNIS [32], que relaciona as quantidades totais RSDs coletadas nos 70 domicílios amostrados e a quantidade média de residentes nesses domicílios.

$$
Q_{\text {percapita }}=\frac{\left(C_{1}+C_{2}+C_{3}\right)}{\frac{N^{\mathrm{a}}{ }_{D}}{M_{h a b .}}}
$$

Onde, $\mathrm{Q}_{\text {per capita }}=$ quantidade de RSDs produzidos por habitante ao dia (kg/hab./dia), $\mathrm{C}_{1}=$ quantidade total de RSDs da primeira coleta $(\mathrm{kg}), \mathrm{C}_{2}=$ quantidade total de RSDs da segunda coleta $(\mathrm{kg}), \mathrm{C}_{3}=$ quantidade total de RSDs da terceira coleta $(\mathrm{kg})$, $\mathrm{N}_{\mathrm{D}}^{\mathrm{a}}=$ número de domicílios amostrados $=70, \mathrm{M}_{\text {hab. }}=$ média de residentes por domicílio amostrado $=4$.

\subsubsection{Comparativo entre a geração per capita experimental e a fornecida pelo SNIS}

A quantidade per capita utilizada para fins de comparação é a de $0,87 \mathrm{~kg} / \mathrm{hab}$./dia, que consta na base de informações do SNIS [32] para o município. O erro relativo entre o valor estimado em campo e o disponibilizado pelo Sistema foi calculado pela equação (3).

$$
e=\frac{Q_{\text {percapita }(S N I S)}-Q_{\text {percapita }}}{Q_{\text {percapita }}} \times 100
$$

Onde, $e=$ erro relativo $(\%), Q_{\text {percapita(SNIS) }}=$ geração per capita do SNIS (kg/hab./dia), 


$$
Q_{\text {percapita }}=\text { geração per capita obtida em campo }
$$

(kg/hab./dia).

\subsubsection{Composição gravimétrica}

A composição gravimétrica foi determinada pela proporção dos componentes: matéria orgânica, plástico, papel, material eletrônico, rejeitos, metal, vidro e outros.

\subsection{Geração diária de RSDs}

A atual produção diária de resíduos no município foi determinada por meio da equação (4) disponibilizada pelo Núcleo Sudeste de Capacitação e Extensão Tecnológica em Saneamento Ambiental [11], com base na população presente na sede, dada pelo último Censo Demográfico [33].

$$
G o=\text { Po.Gpo.Co }
$$

Onde, $G o$ = geração diária atual de resíduos $(\mathrm{kg} / \mathrm{dia})$, Po = população atual total da sede do município = 20.002 hab., Gpo = geração per capita atual (kg/hab./dia) - obtida por amostragem, $\mathrm{Co}=$ cobertura atual da coleta de resíduos no município segundo SNIS $=100 \%$ ou 1 .

\subsubsection{Geração e volume útil para um período de 10 anos}

A geração diária de resíduos para 10 anos de operação de um possível aterro no município, tempo mínimo estipulado pela NBR 13.896/97 [34], foi obtida pela equação (5) adaptada do NUCASE [11]

$$
G_{t}=\left\{\text { Po. }\left(1+\mathrm{y}_{\mathrm{p}}\right)^{\mathrm{t}}\right\} .\{\text { Gpo.Co }\}
$$

Onde, $\mathrm{G}_{\mathrm{t}}=$ geração diária de resíduos, após $\mathrm{t}$ anos $(\mathrm{kg} / \mathrm{dia})$, Po $=$ população atual total da sede do município = 20.002 hab., Gpo = geração per capita atual (kg/hab./dia) obtida por amostragem, Co = cobertura atual da coleta de resíduos no município segundo SNIS $=100 \%$ ou $1, \mathrm{y}_{\mathrm{p}}=$ taxa de crescimento populacional $=0,3 \%$ ou 0,003 a.a., $\mathrm{t}=$ tempo considerado $=10$ anos.

O volume de resíduos que chegaria ao aterro em 10 anos foi calculado pela equação (6) proposta por Oliveira [35].

$$
V=\frac{G_{t}}{\rho}
$$

Onde, $\mathrm{V}=$ volume de resíduos no aterro, após 10 anos ( $\left.\mathrm{m}^{3} / \mathrm{dia}\right), G_{t}=$ geração futura de resíduos, após 10 anos (ton/dia), $\rho=$ peso específico dos resíduos compactados no aterro segundo $\mathrm{NUCASE}=0,8 \mathrm{ton} / \mathrm{m}^{3}$.

\subsubsection{Estimativa da área do aterro de pequeno porte}

Baseando-se no método de execução da trincheira, visto no NUCASE [11], a área a ser aterrada, bem como as dimensões relativas ao comprimento e à largura foram encontradas por meio da altura útil de vala e das equações (7), (8) e (9) dadas por Oliveira [35].

$$
\begin{aligned}
A & =\frac{V}{h}(7) \\
C & =3 . L(8) \\
A & =L . C
\end{aligned}
$$

Onde, $\mathrm{A}=$ área a ser aterrada $\left(\mathrm{m}^{2}\right), \mathrm{V}=$ volume aterrado mensalmente em 10 anos $\left(\mathrm{m}^{3}\right), \mathrm{h}=$ altura útil da vala sugerida por Oliveira [27] $=5 \mathrm{~m}, \mathrm{C}=$ comprimento da trincheira $(\mathrm{m}), \mathrm{L}$ $=$ largura da trincheira $(\mathrm{m})$.

\subsection{Processamento dos dados}

Os dados reunidos em todas as etapas do estudo foram compilados em programa Excel ${ }^{\circledR}$, para devidos cálculos e análises estatísticas. A variância entre as três diferentes coletas gravimétricas foi verificada por teste ANOVA fator único, uma vez que apenas as coletas foram vistas como fator de influência na quantidade de resíduos, durante o intervalo experimental.

\section{Resultados e discussões}

\subsection{Geração per capita}

Os resultados mostraram que há uma produção média de $0,72 \mathrm{~kg} / \mathrm{hab} . / \mathrm{dia}$ de resíduos sólidos dentro da sede municipal (equação 2). Ainda que represente a geração per capita da sede, esse resultado condiz com o valor médio levantado para municípios com faixa populacional de até 30000 habitantes, nos quais a massa coletada per capita fica em torno de 0,76 $\mathrm{kg} / \mathrm{hab} . /$ dia [32]. E com o valor de 0,795 kg/hab./dia estimado para o estado da Bahia [7].

Para três municípios da Paraíba, outro estado nordestino, Silva et al. [36] levantaram uma geração per capita que foi de 0,49 a $0,54 \mathrm{~kg} / \mathrm{hab} . / \mathrm{dia}$. 
Embasadas no intervalo de valores encontrados pelo IBGE em 2010, para a geração diária das cinco grandes regiões brasileiras, Santiago e Dias [37] fixaram o menor valor per capita de $0,84 \mathrm{~kg} / \mathrm{hab} . / \mathrm{dia}$ como o que pode ser considerado sustentável.

\subsection{Comparativo entre a geração per capita experimental e a fornecida pelo SNIS}

$\mathrm{O}$ erro relativo entre a geração per capita dada pelo SNIS e a experimental ficou em torno de $21 \%$ (equação 3 ). Levando-se em conta que o valor per capita experimental de $0,72 \mathrm{~kg} / \mathrm{hab}$./dia corresponde ao quantitativo de resíduos da sede municipal, o erro torna-se aceitável e o valor satisfatório quando comparado com o de $0,87 \mathrm{~kg} / \mathrm{hab}$./dia estimado pelo Sistema Nacional, para todo município.

A proximidade entre a produção média per capita calculada e a produção per capita referente a 2015 indicam certo padrão no quantitativo de resíduos que é gerado por habitante, no intervalo de tempo considerado.

\subsection{Composição gravimétrica}

Conforme ilustra a Figura 3, a maior parte do que é produzido em massa de resíduos sólidos na sede municipal constitui-se de matéria orgânica (M.O), fração tal que ocupa mais de $60 \%$ da composição total.

Em estudo semelhante, Galdino e Martins [38] constataram, a partir da composição gravimétrica de um município de pequeno porte, a presença de $54 \%$ de fração orgânica, percentual considerado alto pelos autores, mas que, segundo eles, é característico de localidades pequenas. Além disso, Alkmin e Ribeiro Junior [39] também encontraram alta predominância de matéria orgânica putrescível em um pequeno município mineiro, que representou 55,6\% do total, em conjunto com $12,7 \%$ de outros tipos de resíduos; $12,2 \%$ de plástico; $11,1 \%$ de papel/papelão; $5,60 \%$ de metal e $2,80 \%$ de vidro.

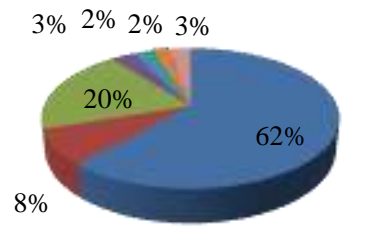

$$
\begin{aligned}
& \text { M.O } \\
& \text { - Plástico } \\
& \text { - Rejeito } \\
& \text { - Papel }
\end{aligned}
$$

Quase toda totalidade de M.O presente nas amostras coletadas adveio da limpeza dos jardins domiciliares, sob a forma de galhos e restos de materiais arbóreos. Isso, provavelmente, deve-se ao fato de grande parte da população sobradinhense possuir o hábito de direcionar os resíduos alimentares ao consumo de animais domésticos e/ou de animais situados em regiões campestres próximas ao município, como relatado por muitos dos residentes, durante a sensibilização participativa do trabalho, e devido à expressiva arborização residencial que gera resíduos e passa a representar grande parte da massa orgânica, o que, de acordo com Soares [40], é "[...] um dado esperado, em função das características culturais dos municípios que mantêm hábitos de limpeza e varrição dos quintais."

Avaliando a percepção das práticas de descarte de resíduos da população no sul de Minas, Franco [31] observou que quase metade da população entrevistada destina seus restos alimentares a animais e que "[...] em cidades de menor porte, o hábito de destinar restos de alimentos aos animais é mais frequente que em municípios de maior porte”.

Oberlin e Szántó [41] alertam que, apesar de países em desenvolvimento como o Brasil possuírem potencial tecnológico para investir em tratamento por compostagem dos resíduos orgânicos, quase nada se sabe sobre como funciona em esfera comunitária e que a ausência de integração municipal torna a técnica influenciável a diversos fatores.

Oliveira e Rodrigues [42] apontam que, embora não haja política de segregação de orgânicos em território brasileiro, a cidade de Florianópolis vem desenvolvendo, com sucesso, projeto sustentável de tratamento desses componentes, apostando em ações de mobilização e sensibilização de famílias e instituições educacionais.

Em termos de variação gravimétrica $(\mathrm{CV})$, ao longo das coletas realizadas, é perceptível a superioridade na quantidade de resíduos orgânicos e a significante estabilidade dessa fração e dos componentes plásticos, rejeito (em maior parte representado por fraldas descartáveis) e papel, na composição geral, como expõe a Tabela 1.

Figura 3- Proporção média entre os componentes dos resíduos analisados. 


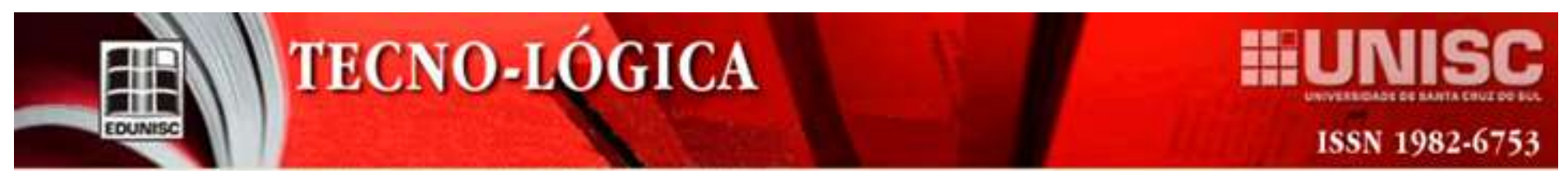

Tabela 1. Valores mensurados para caracterização gravimétrica.

\begin{tabular}{|c|c|c|c|c|c|c|}
\hline Componente avaliado & $1^{a}$ Coleta & $2^{\mathrm{a}}$ Coleta & $3^{\text {a }}$ Coleta & $\begin{array}{c}\text { Média } \\
(\mathrm{kg})\end{array}$ & $\begin{array}{l}\text { MP } \\
\text { (kg) }\end{array}$ & $\begin{array}{l}\mathrm{CV} \\
(\%)\end{array}$ \\
\hline Matéria orgânica & 38,8 & 50,3 & 35,6 & 41,6 & 50,3 & 19 \\
\hline Plástico & 4,9 & 7,1 & 4,6 & 5,5 & 7,1 & 25 \\
\hline Rejeito & 9,8 & 15,8 & 14,3 & 13,3 & 15,8 & 23 \\
\hline Papel & 2,7 & 1,5 & 2,1 & 2,1 & 2,7 & 27 \\
\hline Vidro & 0,4 & 2,6 & 2,2 & 1,7 & 2,6 & 69 \\
\hline Metal & 0,5 & 2,4 & 1,4 & 1,4 & 2,4 & 66 \\
\hline ME & 0,0 & 0,0 & 0,01 & 0,003 & 0,01 & 173 \\
\hline Outros & 2,7 & 2,3 & 0,5 & 1,8 & 2,7 & 65 \\
\hline TP (kg) & 59,7 & 82,1 & 60,6 & & & \\
\hline
\end{tabular}

MP- Máximo produzido; CV - Coeficiente de Variação; TP - Total Produzido; ME - Material Eletrônico.

Também da Tabela 1, e como ilustra a Figura 4, é possível denotar reduzida presença dos componentes vidro, metal, outros (aparos de tecidos, material TNT e etc.) e eletrônico na massa total dos resíduos. Esse último componente, em específico, apresentou alta variação estatística durante o período de análise, isso porque ora houve pequeno descarte, ora não houve descarte algum, supondo não ser comum a população livrar-se do eletrônico via resíduo domiciliar.

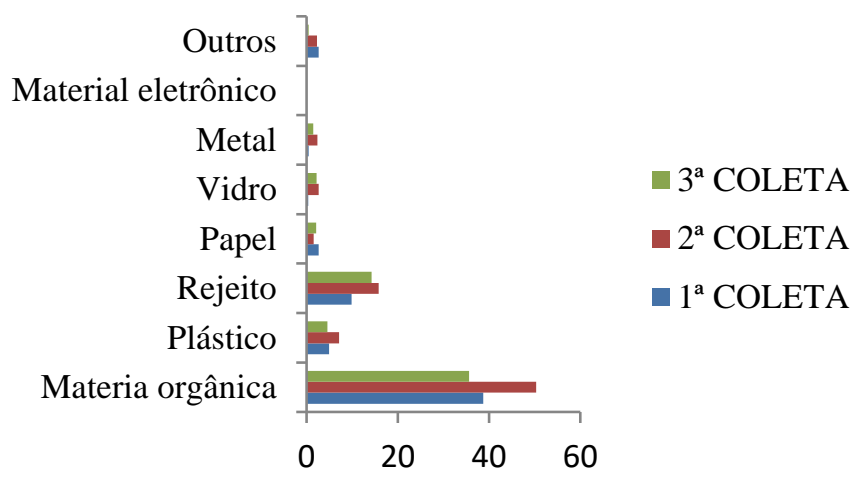

Figura 4 - Oscilações entre as coletas na massa $(\mathrm{kg})$ dos componentes gravimétricos.

Além disso, é importante observar que a maior contribuição dos componentes recicláveis dos tipos plástico e metal, para o total coletado, veio da segunda coleta, realizada no período de festejos juninos.

O teste de análise de variância (ANOVA), em nível de 5\%, demonstrou não ter ocorrido diferenças significativas na quantidade de resíduos no intervalo quinzenal de coleta, pois o valor estatístico de $\mathrm{p}(0,12626)$ ficou $>0,05$, valor tido como padrão de existência de variabilidade (Tabela 2 ).
Tabela 2- Teste de variância entre o número de coletas.

\begin{tabular}{cccccc}
\hline $\begin{array}{c}\text { Fonte } \\
\text { da } \\
\text { Variação }\end{array}$ & $\begin{array}{c}\text { Soma } \\
\text { dos } \\
\text { quadrados }\end{array}$ & $\begin{array}{c}\text { Graus } \\
\text { de } \\
\text { liberdade }\end{array}$ & $\begin{array}{c}\text { Média } \\
\text { quadrática }\end{array}$ & F & Valor-p \\
\hline $\begin{array}{c}\text { Entre } \\
\text { coletas }\end{array}$ & 4827040 & 2 & 241320 & 2,09 & 0,12626 \\
\hline $\begin{array}{c}\text { Dentro } \\
\text { das } \\
\text { coletas }\end{array}$ & 228519504 & 198 & 1154139 & & \\
\hline & 233346543 & 200 & & & \\
\hline Total & 2330 & & & \\
\hline
\end{tabular}

No entanto, é nítido que, em condições absolutas, houve o aumento expressivo na quantidade geral, durante a época festiva, em relação à média de produção (Figura 5), o que pode ter resultado tanto da maior utilização de produtos alimentícios acomodados em embalagens plásticas e/ou metálicas quanto do incremento na quantidade de espigas de milho consumidas, que elevou a massa de M.O contida nos resíduos coletados.

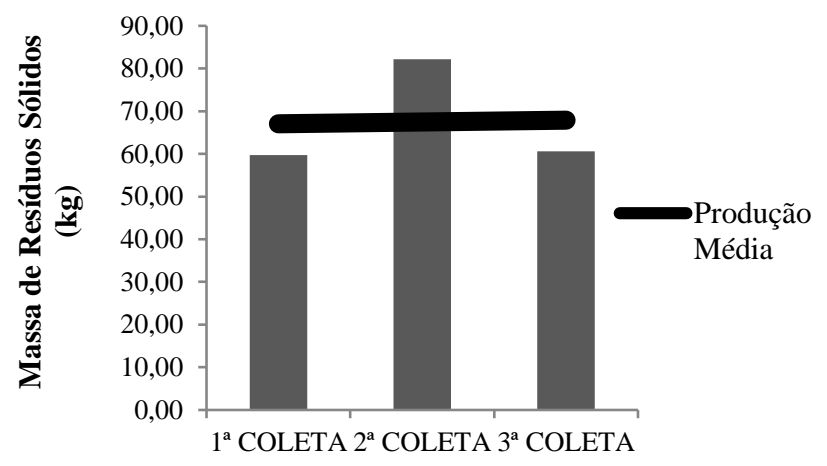

Figura 5 - Total de resíduos produzidos em cada etapa do estudo.

Siqueira et al. [43] afirmam que a geração per capita de um município de pequeno porte alcançou maiores quantidades em períodos que envolveram os meses de dezembro e fevereiro, quando acontece grande fluxo turístico e diferentes eventos.

TECNO-LÓGICA, Santa Cruz do Sul, v. 23, n. 1, p. 49-58, jan./jul. 2019 
Avaliando como se espacializam os componentes passíveis de serem reciclados nas diferentes vilas que configuram a área urbana, é de grande destaque o contingente de plástico descartado pela Vila São Joaquim (SJ), que concentra a maior densidade residencial. E a maioritária participação da Vila Santana (S), com a menor densidade residencial, na concentração de vidro (Figura $6)$.

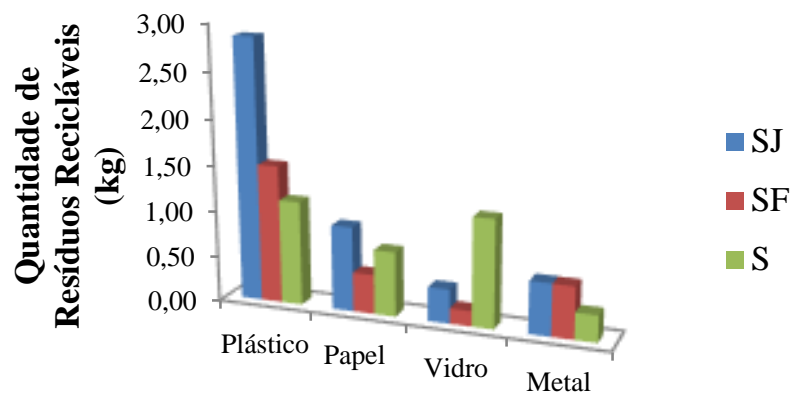

Figura 6 - Produção média total de componentes recicláveis por vilas.

\subsection{Geração diária de RSDs}

Com a população, a cobertura dos serviços de coleta e partindo-se da produção média per capita de $0,72 \mathrm{~kg} / \mathrm{hab} . /$ dia, tem-se que são gerados aproximadamente $14.401 \mathrm{~kg} / \mathrm{dia}(14,4$ ton/dia) de resíduos na sede do município (equação 4).

\subsection{Geração e volume útil para um período de 10 anos}

Seguindo a taxa de crescimento populacional do município e a produção média per capita de $0,72 \mathrm{~kg} / \mathrm{hab}$./dia, foi possível calcular uma geração de aproximadamente $14.839 \mathrm{~kg} / \mathrm{dia}(14,84$ ton/dia) (equação 5) e volume de $18,55 \mathrm{~m}^{3} /$ dia (equação 6) de resíduos para 10 anos de operação do aterro.

\section{6 Área do aterro de pequeno porte}

O volume de resíduos a ser aterrado mensalmente, durante 10 anos, situa-se em $557 \mathrm{~m}^{3}$, sendo preciso aterrar uma área de aproximadamente $111 \mathrm{~m}^{2}$ (equação 7). O terreno contido nessa área deverá dispor de 6,1 m de largura e 18,3 m de comprimento (equações 8 e 9).

\section{Conclusões}

A maior tendência do município em descartar material orgânico, que representa $62 \%$ do total de resíduos coletados, indica que a compostagem pode ser tomada como principal alternativa de tratamento.
É importante destacar que a aderência ao programa de compostagem como forma de tratamento para os $62 \%$ de resíduos orgânicos pode propiciar um aumento no período de vida útil de um provável aterro, que passaria de 10 para aproximadamente 26 anos de operação. Com tal programa unido à presença de coleta seletiva para a porção dos potencialmente recicláveis, é concebível incrementar a vida útil com mais 24 anos, pois, nessa configuração, apenas os rejeitos seriam destinados ao aterro, como estabelece a PNRS.

Embora a produção total para o período estudado tenha se mostrado bastante estável, tornou-se evidente que intervenientes culturais, presentes na região, conseguem ter forte influência no aumento significativo da quantidade coletada e nas características da composição gravimétrica. Isso é fato indicativo de que alternativas técnicas de tratamento, que venham a ser consolidadas, devem ser dimensionadas para operarem considerando esses intervenientes.

Com pouco mais de 20.000 habitantes, o que o enquadra na categoria de municípios de pequeno porte, Sobradinho necessita de possibilidades de destinação final, ambientalmente corretas, dos seus resíduos, que poderiam, inclusive, materializarse por meio de um consórcio intermunicipal para compartilhar a utilização do aterro sanitário pertencente ao município vizinho, Juazeiro-BA. Os esforços direcionados a essas possibilidades precisam ocorrer o mais breve, já que o município não deu início à elaboração de seu Plano Municipal de Gerenciamento Integrado de Resíduos Sólidos (PMGIRS) e recai nos três incisos do artigo $3^{\circ}$, na seção IV da Lei $n^{\circ} 12.305 / 10$, como integrante de área de interesse turístico, com empreendimento de significativo impacto ambiental, que abrange Unidades de Conservação.

Com as informações levantadas e a determinação da área para o aterro, o presente estudo pode contribuir com a elaboração de projetos e/ou programas para o setor municipal de resíduos sólidos, dentro do contexto da obrigatoriedade do município em desenvolver seu Plano de Saneamento, conforme estabelece a Lei $\mathrm{n}^{\circ} 11.445$, no inciso II, do artigo 52.

\section{Agradecimentos}

Os autores agradecem à CAPES, pela concessão das bolsas de pesquisa, à UNIVASF/PROEN, pelo apoio com infraestrutura para pesquisa de campo e à população de Sobradinho. 


\section{PHYSICAL CHARACTERIZATION OF DOMESTIC SOLID WASTE AND DIMENSIONING OF AREA FOR SANITARY LANDING IN THE MUNICIPALITY OF SOBRADINHO-BA}

ABSTRACT: The various disorders promoted by the improper accumulation of Solid Waste due to accelerated population increase, associated with the managerial reality of the country, making the imbalances perceptible. In this context, the present study aimed to perform a physical characterization of household residues and estimate an area dedicated to the implantation of a small landfill for the municipality of Sobradinho-BA. The gravimetric diagnosis was consolidated in three biweekly sessions by door - to - door collections, in 70 households of the municipal headquarters, sampled at $90 \%$ confidence level. The landfill area was estimated from the future production and the per capita generation of the sampled residues. The headquarters generates around $0.72 \mathrm{~kg} / \mathrm{hab} /$ day of SHWs. The total amount obtained consisted of $62 \%$ organic waste, $20 \%$ of tailings, $8 \%$ of recyclable plastic material and $10 \%$ of other types of materials. The greatest increase in mass waste occurred during the June festivities. The estimation of the area for the landfill demonstrated that it is necessary to use $111 \mathrm{~m}^{2}$. The work adds unaccounted information to the city, aiming to contribute with the elaboration of the Basic Sanitation Plan of the Integrated Region of Economic Development.

Keywords: Solid Waste. Gravimetry. Small landfill.

\section{Referências}

[1] BRASIL. Lei ${ }^{\circ} 11.445$ de 5 de janeiro de 2007. Estabelece diretrizes nacionais para o saneamento básico. Presidência da República. 2007.

[2] MI - Ministério da Integração Nacional. Regiões Integradas de Desenvolvimento - RIDEs. Brasília. 2011.

[3] RIDESAB. O que são os Planos de Saneamento Básico das RIDE’s?. Brasília. 2015.

[4] BRASIL. Lei no 12.305 de 2 de agosto de 2010. Institui a Política Nacional dos Resíduos Sólidos. Presidência da República. 2010.

[5] GUERRERO, A, L; MAAS, G; HOGLAND, W. Solid Waste Management Challenges for Cities in Developing Countries. Waste Management, Vol. 33, n. 1, p. 220-232, jan. 2013.

[6] MARSHALL, E, R; FARAHBAKHSH, K. Systems Approaches to Integrated Solid Waste Management in Developing Countries. Waste Management, Vol. 33, n. 4, p. $988-1003,2013$

[7] ABRELPE. Panorama dos resíduos sólidos no Brasil 2015. Associação Brasileira das Empresas de Limpeza Pública e Resíduos Especiais. 2015.

[8] BAHIA. Secretária de Desenvolvimento Urbano - SEDUR. Regionalização da Gestão Integrada de Resíduos Sólidos do Estado da Bahia. Bahia. 2014.
[9] GUEVARA, M. D.F. et al. Escolha de áreas potenciais para localização de um aterro sanitário no município de Pelotas/RS utilizando Sistema de Informações Geográficas. Tecno-Lógica, Santa Cruz do Sul, Vol. 21, n. 2, p. 80-90, 2017.

[10] PORTELLA, M. O.; RIBEIRO, J. C. J. Aterros sanitários: aspectos gerais e destino final dos resíduos. Revista Direito Ambiental e Sociedade, Vol. 4, n. 1, p. $115-134,2014$

[11] NUCASE- Núcleo Sudeste de Capacitação e Extensão Tecnológica em Saneamento Ambiental. Projeto, operação e monitoramento de aterros sanitários. Guia do profissional em treinamento, nível 2. 2013.

[12] KROETZ, C.E. Desenvolvimento de um sistema de apoio ao dimensionamento e estimativa de custos de aterros sanitários em trincheiras para municípios de pequeno porte. Florianópolis, 2003. 159p. Dissertação (Mestrado em Engenharia Ambiental) - Universidade Federal de Santa Catarina, Florianópolis, 2003 .

[13] IBAM-INSTITUTO BRASILEIRO DE ADMINISTRAÇÃO MUNICIPAL. Manual de Gerenciamento Integrado de Resíduos Sólidos. Rio de Janeiro. 2001.

[14] CAMPOS, H. K. T. Renda e evolução da geração per capita de resíduos sólidos no Brasil. Revista Engenharia Sanitária e Ambiental, Vol. 17, n. 2, p. 171-180, 2012 .

[15] FRANCO, D.; CASTILHOS JUNIOR, A. B. DE; SOUZA, K. da S. de. Estudo da relação entre a geração de resíduos sólidos domiciliares e o consumo de água e energia elétrica: alternativas de tarifação da coleta de resíduos sólidos. Revista Brasileira de Gestão e Desenvolvimento Regional, Taubaté, Vol. 10, n. 4, p. 201224, 2014.

[16] COLVERO, D. A. et al. Avaliação da geração de resíduos sólidos urbanos no estado de Goiás, Brasil: análise estatística de dados. Revista de Engenharia Sanitária e Ambiental, Rio de Janeiro, Vol. 22, n. 5, p. 931-941, 2017.

[17] SOUZA, G. F. C.; TINÔCO, M. S. Avaliação do lixo marinho em costões rochosos na Baía de todos os Santos, Bahia, Brasil. Revista da Gestão Costeira Integrada, Vol. 1, p. 135-143, 2011.

[18] OLIVEIRA, C. E. S. et al. Estudo gravimétrico do aterro sanitário do município de Caruaru-PE. Anais do Congresso Brasileiro de Gestão Ambiental e Sustentabilidade - Vol. 3: Congestas 2015

[19] MIEZAH, K. et al. Municipal solid waste characterization and quantification as a measure towards effective waste management in Ghana. Waste Management, Vol. 46, p .15-27, 2015.

[20] GU, B. et al. Characterization, quantification and management of China's municipal solid waste in spatiotemporal distributions: a review. Waste Management, Vol. 61, p. 67-77, 2017.

[21] CARVAlHO, J. L. V.; JESUS, S.C.; PORTElA, R. B. Composição gravimétrica dos resíduos sólidos domiciliares e comerciais do centro da cidade de Barreiras-BA. Chão Urbano (Online), Vol. XII, p. 1-14, 2013.

[22] BRASIL. IBGE - Instituto Brasileiro de Geografia e Estatística. Bahia. Sobradinho. 2017. Disponível em: 〈www.ibge.gov.br >. Acesso em: 10 ago. 2017.

[23] SOBRADINHO. Lei ${ }^{\circ} 449 / 2009$. Dispõe sobre o desenvolvimento urbano no município de Sobradinho, institui o seu Plano Diretor Urbano e dá outras providências. Prefeitura Municipal de Sobradinho. 2009.

[24] A Cidade. 2014. Disponível em: <http://www.sobradinho.ba.gov.br/?sessao=informacao\&cod_informacao=2>. Acesso em: 12 jun. 2017.

[25] BRASIL. SNIS - Sistema Nacional de Informações sobre Saneamento. Secretaria Nacional de Saneamento Ambiental. SNIS - Série Histórica 2015. 2015. 


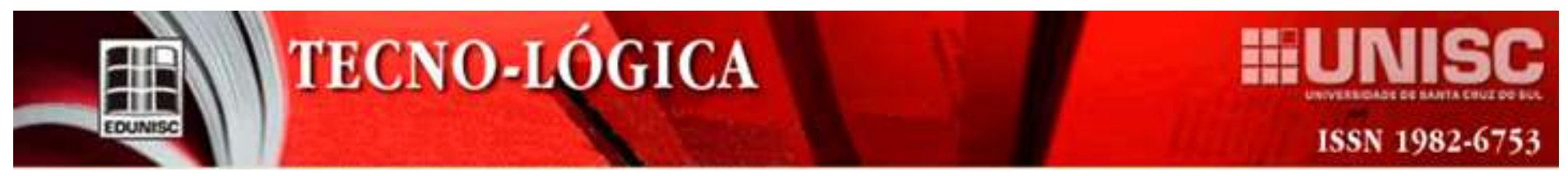

[26] —. MI - Ministério da Integração Nacional. Região Integrada de Desenvolvimento - RIDE Petrolina-Juazeiro. Brasília. 2011.

[27] PALMA, I.R. Análise da Percepção como Instrumento ao Planejamento da Educação Ambiental. Porto Alegre, 2005. 39 p. Dissertação (Pós-Graduação em Engenharia de Minas, Metalúrgica e de Materiais) - Universidade Federal do Rio Grande do Sul. 2005

[28] DAHLEN, L.; LAGERKVIST, A. Methods for house waste composition studies. Waste Management, Vol. 28, n.7, p. 1100-1112. 2008.

[29] BASSANI, P. D. Caracterização de resíduos sólidos de coleta seletiva em condomínios residenciais: estudo de caso em Vitória-ES. Vitória, 2011. 187 p. Dissertação (Pós-Graduação em Engenharia Ambiental) - Universidade Federal do Espírito Santo. 2011.

[30] ABNT - ASSOCIAÇÃO BRASILEIRA DE NORMAS TÉCNICAS. NBR 10007: Amostragem de resíduos sólidos. Rio de Janeiro, 2004. 21p.

[31] FRANCO, C. S. Caracterização Gravimétrica dos Resíduos Sólidos Domiciliares e percepção dos hábitos de descarte no sul de Minas Gerais. Lavras, 2012. 157p. Dissertação (Pós-Graduação em Engenharia Agrícola) - Universidade Federal de Lavras. 2012.

[32] BRASIL. SNIS - Sistema Nacional de Informações sobre Saneamento. Secretaria Nacional de Saneamento Ambiental. Diagnóstico do Manejo de Resíduos Sólidos Urbanos 2015. 2015.

[33] BRASIL. IBGE - Instituto Brasileiro de Geografia e Estatística. Censo demográfico. 2010. Disponível em: <www.ibge.gov.br >. Acesso em: 10 ago. 2017.

[34] ABNT - ASSOCIAÇÃO BRASILEIRA DE NORMAS TÉCNICAS. NBR 13896: Aterros de resíduos não perigosos - Critérios para projeto, implantação e operação. Rio de Janeiro, 1997. 12p.

[35] OLIVEIRA, L. D. de. Projeto de aterros sanitários. Universidade Estadual de Maringá - Departamento de Engenharia Civil. 2015. 44 slides. Apresentação em Power-point.

[36] SILVA, M. M. P. da et al. Avaliação sanitária de Resíduos Sólidos Orgânicos Domiciliares em municípios do semiárido paraibano. Revista Caatinga, Vol. 23, n. 2, p. 87-92, 2010.

[37] SANTIAGO, L. S.; DIAS, S. M. F. Matriz de indicadores de sustentabilidade para a gestão de Resíduos Sólidos Urbanos. Revista de Engenharia Sanitária e Ambiental, Rio de Janeiro, Vol. 17, n. 2, p. 203-212, 2012.

[38] GALDINO, S. de J.; MARTINS, C. H. Composição gravimétrica dos Resíduos Sólidos Urbanos da coleta convencional de um município de pequeno porte. Tecno-Lógica, Santa Cruz do Sul, Vol. 20, n. 1, p. 01-08, 2016.

[39] ALKMIN, D.V.; RIBEIRO JUNIOR, L. U. Determinação da composição gravimétrica dos Resíduos Sólidos Urbanos (RSU) do lixão do município de Maria da fé, estado de Minas Gerais. Caminhos de Geografia, Uberlândia, Vol. 18, n. 61, p. $65-82,2017$.

[40] SOARES, A. P. Caracterização gravimétrica dos resíduos sólidos do baixo Jequitinhonha / Minas Gerais - instrumento para gestão e gerenciamento de resíduos sólidos urbanos sob perspectiva regional. In: Congresso Brasileiro de Gestão Ambiental, IV. Salvador. 2013.

[41] OBERLIN, A. S.; SZÁNTÓ, G.L. Community level composting in a developing country: case study of KIWODET, Tanzania. Waste Management \& Research, Vol. 29, n. 10, p.1071-1077, 2011.

[42] OLIVEIRA, C. T. de; RODRIGUES, C. M. T. Sistema de coleta de resíduos orgânicos em nível comunitário em um país em desenvolvimento: estudo de caso em Florianópolis, Brasil. Revista Metropolitana de Sustentabilidade, São Paulo, Vol. 7, n. 2, p. 152-169, 2017.
[43] SIQUEIRA, H. E. et al. Composição gravimétrica dos Resíduos Sólidos Urbanos na cidade de Nova Ponte (MG). Revista DAE, n. 202, 2016. 